\title{
Coligações eleitorais e fragmentação das bancadas parlamentares no Brasil: simulações a partir das eleições de 2014
}

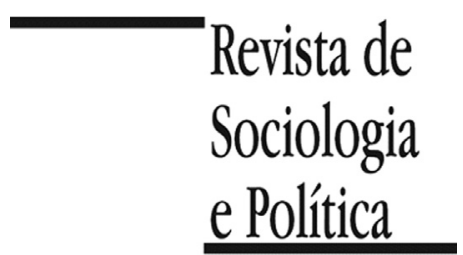

DOI $10.1590 / 1678-987316246003$

\author{
Luis Felipe Miguel e \\ Pedro Paulo Ferreira Bispo de Assis
}

\section{Resumo}

O artigo discute o impacto das coligações eleitorais na fragmentação das bancadas partidárias na Câmara dos Deputados brasileira. Com base nos dados do Tribunal Superior Eleitoral, sobre as eleições para Câmara dos Deputados em 2014, simulamos e comparamos quatro arranjos alternativos na tradução das votações em cadeiras. A simulação revela que, sem as coligações, tanto o número de partidos com representação na Câmara quanto o índice de fracionarização de Rae cairiam $21 \%$. Ainda que a simulação possua limitações, já que a mudança nas regras mudaria também as estratégias dos agentes políticos, fica demonstrado que o veto às coligações reduziria a dispersão das cadeiras parlamentares, sem implicar a adoção de medidas arbitrárias (como a introdução de uma cláusula de exclusão). Pelo contrário, o banimento das coligações contribuiria para aproximar o sistema eleitoral da lógica que preside a representação proporcional.

PALAVRAS-CHAVE: coligações eleitorais; eleições brasileiras; partidos políticos; representação proporcional; reforma eleitoral.

Recebido em 4 de Maio de 2015. Aceito em 9 de Julho de 2015.

\section{Introdução}

${ }^{1}$ Os autores agradecem as críticas e sugestões dos pareceristas anônimos da Revista de Sociologia e Política. Continuamos, é claro, como os únicos responsáveis pelas falhas e omissões do texto.

\footnotetext{
${ }^{2}$ Embora, no sistema misto alemão, as cadeiras conquistadas na votação majoritária sejam irredutíveis; a cláusula de barreira se aplica apenas às cadeiras distribuídas de forma proporcional. Para uma resenha do uso da cláusula de barreira em
}

purados os votos das eleições brasileiras de 2014, constatou-se que o número de partidos com representação na Câmara dos Deputados tinha 1 batido um novo recorde ${ }^{1}$. Nada menos que 28 diferentes legendas haviam conquistado cadeiras. A maior bancada, a do Partidos dos Trabalhadores, não ultrapassou 70 deputados, menos de 15\% do total. Por outro lado, dez partidos ficaram com bancadas de cinco deputados ou menos. $\mathrm{O}$ fato fez reviver o velho diagnóstico de que o número excessivo de partidos é um dos problemas crônicos da democracia brasileira e um dos obstáculos centrais à chamada "governabilidade". A começar pelo presidente do Tribunal Superior Eleitoral (TSE), ministro José Antônio Dias Toffoli, vozes se levantaram a favor da introdução da cláusula de barreira, outra ideia sempre presente nos debates sobre reforma política, que permitiria a redução do número de legendas com representação parlamentar por um simples ato de vontade do legislador.

A cláusula de barreira pode assumir diferentes feições; a mais radical excluiria do poder Legislativo os partidos que não tivessem obtido um percentual mínimo de votos (em geral, fala-se em 5\%, a exemplo do que ocorre na Alemanha)². A Lei dos Partidos Políticos aprovada em 1995 (Lei 9.096/95) determinava restrições mais brandas, mas ainda assim repletas de consequências para os partidos pequenos, limitando seu funcionamento no Congresso (não indicariam membros titulares nas comissões) e reduzindo o acesso ao fundo partidário e ao espaço de propaganda no rádio e na televisão. O Supremo Tribunal Federal (STF) considerou inconstitucionais as restrições. De fato, mesmo desta forma mitigada, a cláusula de barreira introduz assimetrias na competição política e no exercício da atividade parlamentar, ferindo os princí- 
diferentes países, ver Rodrigues (1994). pios da isonomia e da soberania popular. Os partidos menores teriam cerceada sua possibilidade de participar da disputa e o eleitor que escolhesse ser representado por eles ganharia um representante "pela metade", por assim dizer.

Em geral, argumenta-se como se não existisse cláusula de barreira no Brasil. No entanto, os partidos ou coligações que não alcançam o quociente eleitoral são excluídos da distribuição das cadeiras restantes. Isso significa uma barreira variável, de acordo com a magnitude do distrito, que fica em 1,4\% dos votos válidos em São Paulo e alcança 12,5\% nas 11 unidades da federação que elegem apenas oito deputados federais cada. Em situações de grande fragmentação da votação partidária, como é o caso do Brasil, trata-se de uma regra que tem impacto significativo na composição das bancadas. O que por vezes é sugerido, como novidade, é a introdução de uma barreira nacional, penalizando os partidos com menor votação no eleitorado total do país.

A introdução de critérios de exclusão dos partidos menores é defendida com base em seus efeitos para a chamada governabilidade e também para a "legibilidade" do sistema partidário pelos eleitores comuns. Duas expressões enfáticas estão em Tavares (1994) e Mainwaring (2001). Ambos concordam no entendimento de que o grande número de partidos é o principal desafio a ser enfrentado para o aprimoramento da democracia no Brasil. Tantos partidos no Congresso exigem um esforço muito grande de negociações e concessões para que o poder Executivo obtenha a maioria necessária para governar. E tantos partidos nas eleições não tornam razoável esperar que os cidadãos sejam capazes de avaliar as ofertas que estão à sua disposição. Um sistema partidário mais enxuto facilitaria a vida tanto de governos quanto de eleitores. Com maiorias mais claras e uma oferta menor, o eleitorado seria capaz de atribuir com mais clareza as responsabilidades, melhorando o funcionamento dos mecanismos de accountability.

Mas o peso atribuído ao sistema partidário, na explicação das insuficiências de nossa democracia, é próprio de uma Ciência Política excessivamente focada nas instituições. Outros fatores, como a influência do poder econômico, o controle da informação ou o desincentivo estrutural à participação e à educação políticas, certamente mais cruciais, são deixados de lado (Miguel 2010). Mesmo nos seus próprios termos, porém, o remédio da redução dos partidos é problemático. Pensando os desafios do poder Executivo para a construção de maiorias, à luz da teoria de partidos, é possível compreender que os problemas não se resumem só ao número deles (Duverger 1980) ou à engenharia para uni-los em coalizões de governo. Esses impasses estão ligados ao fato de que as bancadas partidárias são pouco coesas e, em grande medida, os apoios precisam ser negociados seletivamente, nas dimensões interpartidária e intrapartidária. Todos os governos posteriores à redemocratização tiveram de lidar com isso.

Há esforço de parte da literatura para mostrar, com base nos registros de votações no Congresso, que as bancadas partidárias no Brasil são bem mais coesas do que se supõe (Limongi \& Figueiredo 1995; Limongi 2006). Tal conclusão é contestada quando o foco é concentrado nas questões polêmicas e se leva em conta o comportamento estratégico que retira da deliberação as propostas cujo fracasso é antecipado (Ames 2003). A presente discussão, no entanto, passa ao largo da polêmica: mesmo que as bancadas votem de forma coesa, tal coesão é resultado de múltiplas negociações e trocas de favores particularizados. Os indícios de que a coesão é motivada pela disciplina, isto é, pelo controle de recursos pelos chefes partidários (Limongi \& Figueiredo 1998), são frágeis e contraditos pelo peso das bancadas informais suprapartidárias, pelas constantes formações de blocos subpartidários que negociam, cada um por si, com o poder Executivo e, enfim, pela observação do comportamento cotidiano dos parlamentares. 
Da mesma maneira, os partidos representam pouca informação em uma competição eleitoral focada nos candidatos. Isto é, a lógica de apoio fortemente estruturada pela alocação de recursos seletivos e pela personalização da competição política parecem ser desafios parelhos à constituição de maiorias e à inteligibilidade da disputa eleitoral que o número excessivo de legendas.

O primeiro efeito de uma redução como a usualmente proposta seria o fortalecimento das direções partidárias, já que o acesso à candidatura por uma legenda forte seria um bem mais concorrido do que é hoje. É talvez um passo na direção da consolidação da identidade dos partidos. Mas cabe lembrar que os partidos brasileiros em geral possuem direções oligárquicas, com pouca abertura interna. $\mathrm{O}$ reforço desses grupos não necessariamente é benéfico à democracia.

Ainda mais grave é o fato de que a exclusão dos pequenos partidos pode reduzir a representatividade do poder Legislativo. Se as únicas preocupações fossem a formação de maiorias sólidas e a facilidade de atribuição de responsabilidade pelas políticas, sem dúvida um sistema de partido único seria o mais desejável. A busca por representatividade, por outro lado, indica que os diferentes interesses sociais devem estar presentes no parlamento, a fim de participar do debate público, defender suas propostas e participar das negociações legislativas. Do ponto de vista do eleitor, ter um cardápio mais amplo de alternativas à disposição permite um ajuste mais fino na expressão de suas preferências e estimula a responsividade dos representantes (Miguel 2014, cap.6). Em suma, uma representação democrática responsiva não se resume à eficácia governamental. Passa, antes, pelo ajuste fino de uma oferta do mercado político que se adeque à pluralidade de perspectivas sociais dos cidadãos. A diversidade de um mercado político reflete seu nível competitivo. Subverter essa dinâmica em favor de um arranjo homogeneizador das legendas é simplificar a tomada de decisão em detrimento da sua substância representativa.

É possível pensar que a exclusão das chamadas "legendas de aluguel", os pequenos partidos que buscam nichos nos mercados políticos locais sem qualquer identidade programática, pouco afetaria a representatividade parlamentar. Mas a cláusula de barreira termina por inviabilizar também as pequenas legendas ideológicas ou programáticas, que buscam representar interesses sociais e correntes de opinião claramente definidos. A distinção aqui esgrimida segue aquela do senso comum, mas é digna de atenção. Representantes expressam interesses, valores ou opiniões, para usar a tipologia celebrizada por Young (2000). Quando um partido se vincula com alguma clareza a um ou mais destes elementos, pertence ao universo do que estamos chamando de legendas programáticas ou ideológicas. Quando é simplesmente um meio para viabilizar a candidatura de alguns indivíduos, resvala para a caracterização como "legenda de aluguel". Os primeiros cumprem papel como balizadores da disputa política e organizadores da pressão da sociedade sobre o Estado, ainda que disponham de base social pequena. Os segundos, não.

A exclusão dos partidos ideológicos ou programáticos reduziria a qualidade do debate político e representaria silenciar vozes que têm o direito de ser escutadas. Para gerar uma discussão democrática mais densa, é conveniente incorporar múltiplas posições, não afastá-las. Seria possível justificar até mesmo um sistema hipotético que garantisse a participação no debate das correntes de pensamento que não possuem peso eleitoral suficiente - uma anticláusula de barreira, por assim dizer. Mas a exclusão por conta de um limite arbitrariamente fixado fere o princípio de que um debate plural é condição para a democracia.

Há uma alternativa para caminhar na direção da redução do número de partidos, que não possui efeitos colaterais adversos e é condizente com um entendimento teórico-normativo sólido da representação política: a proibição 
${ }^{3}$ A relação de siglas e seus significados encontra-se no Apêndice 1, ao final do texto. das coligações em eleições proporcionais. A rationale da representação proporcional é dar a cada corrente política uma participação no parlamento que corresponda à sua participação no eleitorado. A clássica defesa que John Stuart Mill fez da representação proporcional (e, antes dele, Thomas Hare) já indicava com clareza o argumento. Trata-se de permitir que os eleitores escolham seus deputados por afinidade de propostas e ideias, não apenas por compartilharem a região de moradia, como ocorre no sistema de votação majoritária em circunscrições uninominais, o chamado "voto distrital" (Mill 1995, p.93).

As coligações distorcem tal correspondência e trabalham contra a lógica que deveria reger o sistema proporcional, como já anotou Tavares (1994). O eleitor escolhe o partido, encarnação dos valores, opiniões e propostas que gostaria de ver presentes no poder Legislativo, mas ajuda, com seu voto, a eleger alguém de um partido diverso. As coligações geram, assim, uma transferência quase lotérica dos sufrágios, retirando a homologia entre vontade popular e representação no parlamento que o sistema busca.

Algumas coligações podem ser vistas como dotadas de razoabilidade, como aquelas operadas entre partidos grandes e seus satélites tradicionais (PT e PCdoB, PSDB e DEM ${ }^{3}$ ) - ainda assim, a transferência de votos pode implicar em falseamento da vontade popular. Na maior parte dos casos, porém, as coligações não passam de arranjos circunstanciais que não configuram nenhuma corrente de opinião a ser representada e que só são possíveis graças ao alto grau de personalização da campanha. Apenas como exemplo, no Distrito Federal, em 2014, estiveram juntos, para a Câmara dos Deputados, PT, PCdoB, PP, PRB, PROS e PSC. A lista elegeu dois candiatos, ambos reeleitos: Erika Kokay (PT), cujo mandato se fez em defesa das mulheres e das minorias, e o Pastor Ronaldo Fonseca (PROS), com discurso antiabortista, homofóbico e, como proclamava na campanha, em defesa da "soberania de Deus". Os votos de uma ajudaram a eleger o outro.

Da forma como se configura a disputa eleitoral no Brasil, a coligação nas eleições proporcionais é usada, em primeiro lugar, como moeda de troca para obter apoios nas eleições majoritárias. O partido menor contribui com seu tempo de propaganda eleitoral na disputa para governador (ou prefeito) e ganha a possibilidade de "pegar carona" na chapa do partido maior para as proporcionais. Concentrando sua campanha em poucos candidatos, tem chance de posicioná-los bem na lista e, assim, obter cadeiras. Trata-se de um arranjo que é racional para as legendas envolvidas, mas compromete a simetria entre apoio a correntes de opinião e bancadas legislativas, pretendida pela representação proporcional.

Em vez de determinar uma barreira arbitrária, a proibição de coligações contribuiria para reduzir o número de partidos representados seguindo a lógica da representação proporcional. Incidiria sobre as legendas de aluguel, mas preservaria os pequenos partidos programáticos, que são os que tendem a participar menos de coligações. Nas duas próximas seções, exploramos quatro arranjos alternativos e indicamos que a proibição das coligações teria efeitos mecânicos imediatos na redução do número de partidos com cadeiras e do fracionamento da Câmara dos Deputados. Na conclusão, apontamos os limites dessa medida, que pode ser necessária, mas certamente é insuficiente para gerar uma representação política democrática qualificada.

\section{Coligações e fragmentação partidária na Câmara dos Deputados}

A fragmentação das bancadas na Câmara é uma característica do pluripartidarismo brasileiro. Em 1982, sob o plurapartidarismo limitado do final da ditadura, com uma legislação que penalizava fortemente as legendas menores (o 
${ }^{4}$ No entanto, caso 513 diferentes partidos tivessem obtido uma cadeira cada, a probabilidade de que dois deputados escolhidos aleatoriamente pertencessem a partidos diferentes seria de $100 \%$. "voto vinculado", que atrelava a escolha dos deputados ao partido do candidato a governador), todos os cinco partidos legais obtiveram cadeiras. O PDS obteve um pouco menos da metade da Câmara dos Deputados, seguido de perto pelo PMDB. Com a redemocratização e a explosão no número de legendas que competiam, a fragmentação se ampliou de forma significativa. Como mostra a Tabela 1, os números oscilam em patamares muito elevados de dispersão (muitos partidos representados, poucas bancadas grandes, alto índice de fracionamento de Rae) e mostram uma tendência nítida, embora não unívoca, de ascensão destes patamares.

Na Tabela 1, os partidos necessários para a maioria simples são calculados aritmeticamente, sem levar em conta as posições nas disputas ideológicas. O índice de fracionamento de Douglas Rae é calculado a partir do somatório dos quadrados das frações do parlamento em mãos de cada partido e oscila entre zero (concentração absoluta, isto é, um único partido controla todas as cadeiras) e 1 (dispersão máxima das cadeiras). Alguns autores descrevem o índice como sendo "a probabilidade de que dois deputados de um Parlamento [escolhidos aleatoriamente] pertençam a partidos diferentes" (Nicolau 2005, p.599), mas isso é apenas uma aproximação. A rigor, o índice 1 só é alcançado se infinitas cadeiras estão distribuídas entre infinitos partidos. Para a Câmara dos Deputados brasileira atual, com 513 cadeiras, a dispersão máxima alcançável seria de 0,9984. Nicolau (2005) contrasta índices de dispersão parlamentar e afirma a superioridade do número efetivo de partidos de Laakso e Taagepera sobre a fracionamento de Rae. É um índice que toma a mesma base, mas aplica um cálculo diverso e oscila entre 1 (se um único partido controla todas as cadeiras) e infinito (se infinitas cadeiras se distribuem entre infinitos partidos). A vantagem apontada - "pode ser visualizado mais facilmente como número de partidos do que o índice abstrato de Rae" (Lijphart apud Nicolau 2005, p.600) - possui suas próprias contraindicações. Dizer, por exemplo, que existem 3,72 "partidos efetivos" é profundamente contraintuitivo (o que seria 0,72 partido?) e insere uma ideia de efetividade que simplesmente não é capturada pela medição e, portanto, é espúria. Em suma, acreditamos que a opção por um ou outro índice não alteraria a interpretação dos dados e é, em última análise, sobretudo de caráter estético.

O único ponto fora da curva é a eleição de 1986. No bojo do Plano Cruzado, o PMDB obteve a maioria da Câmara Federal, com 260 das 487 cadeiras então em disputa. Obteve também 22 dos 23 governos estaduais, levando comentaristas mais afoitos predizerem a "mexicanização" do Brasil (uma referência ao amplo domínio do PRI nas eleições mexicanas, que, no entanto, começaria a declinar em 1989). A partir de 1990, porém, já fica claro o padrão de grande dispersão das bancadas, que se repete em todas as eleições posteriores.

Cabe observar também que, se para todo o período da redemocratização a tendência para a maior dispersão não é unívoca, com pequenos retraimentos em 1994 e 1998, o mesmo não se pode dizer das eleições que coincidem com as

Tabela 1 - Evolução da fragmentação partidária na Câmara dos Deputados brasileira (1986-2014)

\begin{tabular}{lcccccccc}
\hline & 1986 & 1990 & 1994 & 1998 & 2002 & 2006 & 2010 & 2014 \\
\hline Número de partidos & 12 & 19 & 18 & 18 & 19 & 21 & 22 & 28 \\
Maior bancada & 260 & 108 & 107 & 105 & 91 & 89 & 88 & 70 \\
Partidos para maioria simples & 1 & 4 & 3 & 3 & 4 & 4 & 4 & 5 \\
Fracionamento de Rae & 0,647 & 0,885 & 0,877 & 0,860 & 0,882 & 0,892 & 0,904 & 0,924 \\
\hline
\end{tabular}

Obs: Foram contabilizadas as bancadas no momento da eleição.

Fonte: Os autores, a partir do Tribunal Superior Eleitoral e da Câmara dos Deputados. 
vitórias presidenciais do PT. Os dados de 2002 a 2014 revelam um aumento contínuo tanto do número de partidos que elegem deputados quanto do índice de fracionamento de Rae, acompanhado pela redução contínua do tamanho da maior bancada. É possível especular - mas apenas especular - que isso é consequência da maior dificuldade de os governos petistas garantirem maiorias parlamentares, dado o relativo isolamento do partido durante seu período oposicionista e a necessidade sempre renovada de sustar a desconfiança que setores do capital ainda mantêm em relação a ele. Com isso, o governo teve de ceder mais na negociação com o Congresso, tornando atraente a barganha mesmo para quem controlava bancadas diminutas.

Em todas as eleições presentes na tabela houve ampla liberdade para as coligações partidárias - com a exceção, muito parcial, de 2002, quando imperou a regra da "verticalização", que não impedia as coligações, mas obrigava que se seguisse um mínimo de coerência em nível nacional. Trata-se, então, de saber em que medida as coligações contribuíram para a dispersão das bancadas parlamentares. Os dados apresentados a seguir simulam os resultados da eleição de 2014 caso não fossem permitidas coligações nas eleições proporcionais.

Os dados foram obtidos do Tribunal Superior Eleitoral por meio do software Divulga, disponibilizado pelo tribunal na internet, no período das eleições (e cujo provedor saiu do ar poucas semanas depois). O valor da simulação é certamente limitado, pois caso as regras fossem outras, as estratégias dos agentes políticos também se modificariam. Talvez a mudança no comportamento político reforçasse a tendência de enxugamento do número de bancadas, já que os candidatos com maior potencial eleitoral teriam estímulo para buscar os partidos maiores, em vez de colonizar legendas pequenas e contar com a coligação para obter o quociente eleitoral. Mas isso, evidentemente, permanece também no terreno da especulação.

A Tabela 2 apresenta o quadro geral da composição partidária das Câmara dos Deputados, a partir das eleições de 2014, em dois cenários diferentes. O primeiro é o resultado efetivo, sob a regra eleitoral atual, com a permissão de coligações. O segundo é o cenário hipotético, em que as votações dos candidatos e das legendas teriam sido as mesmas, mas as coligações não vigorariam. É importante lembrar que, no Amapá, nenhum partido obteria sozinho o quociente eleitoral, tamanha foi a dispersão dos votos dentro das coligações. O PT, que recebeu a maior quantidade de sufrágios amapaenses (41.218 votos), ainda assim ficou cerca de 7 mil votos abaixo do quociente. Em concordância com a legislação em vigor, neste caso são considerados eleitos os candidatos mais votados individualmente, sem levar em conta o somatório da legenda, o que foi adotado na simulação.

Observa-se, pela Tabela 2, que há uma retração de todos os índices de dispersão das bancadas, quando é simulada a proibição de coligações. Seis partidos deixariam de estar presentes na Câmara dos Deputados. Já a Tabela 3

Tabela 2 - Fragmentação partidária na Câmara dos Deputados brasileira (2014), de acordo com regras eleitorais alternativas (atual e sem possibilidade de coligações)

\begin{tabular}{lccc}
\hline & Regra atual & Sem coligações & Alteração \\
\hline Número de partidos & 28 & 22 & -6 \\
Maior bancada & 70 & 101 & +31 \\
Partidos para maioria simples & 5 & 3 & -2 \\
Fracionamento de Rae & 0,924 & 0,883 & $-0,041$ \\
\hline
\end{tabular}

Fonte: Os autores, a partir de dados do Tribunal Superior Eleitoral. 
Tabela 3 - Bancadas partidárias na Câmara dos Deputados brasileira (2014), de acordo com regras eleitorais alternativas (atual e sem possibilidade de coligações)

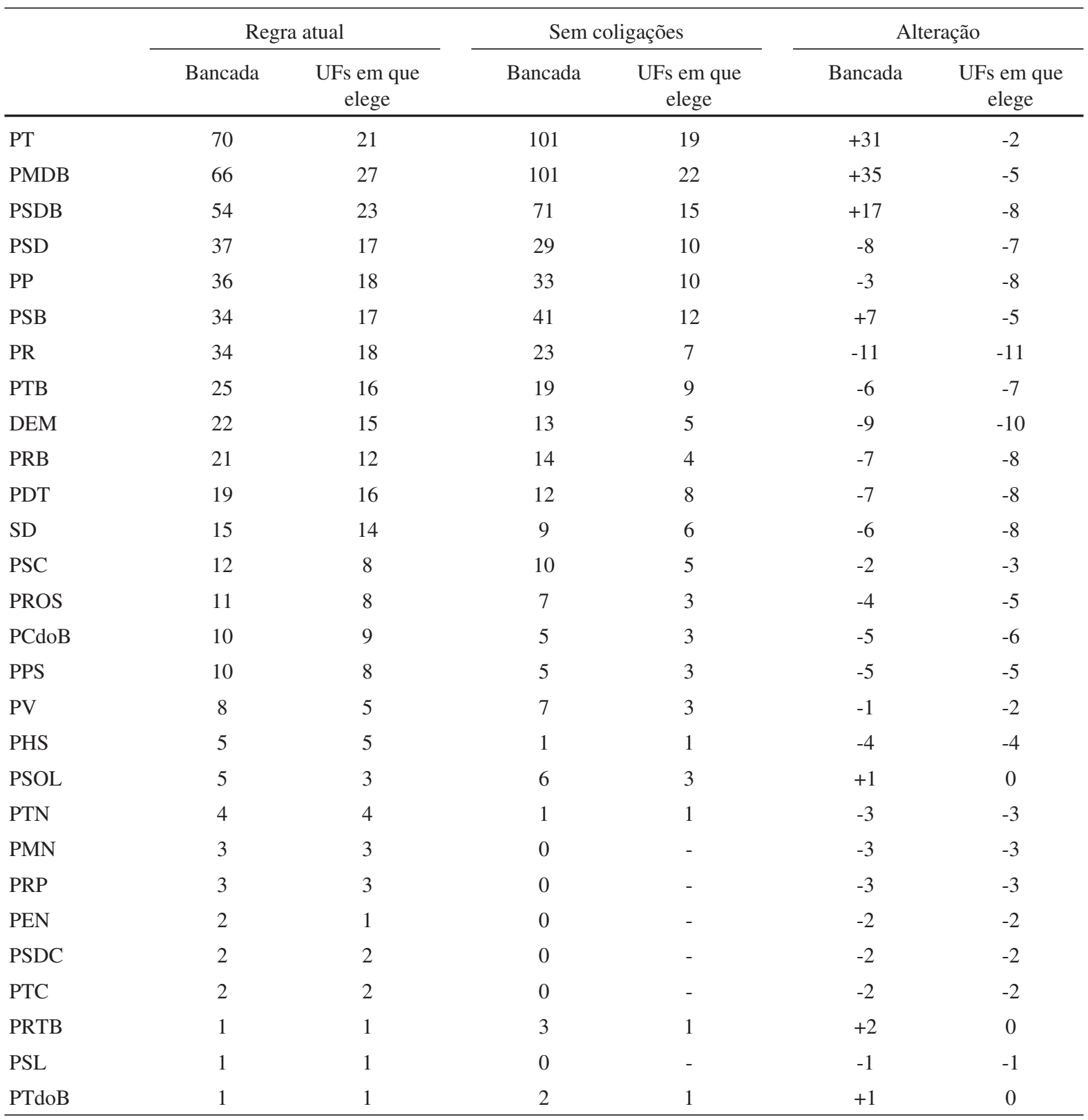

Fonte: Os autores, a partir de dados do Tribunal Superior Eleitoral.

apresenta a composição das bancadas partidárias de acordo com a simulação, em contraste com os resultados oficiais de 2014.

Os grandes beneficiados, com o resultado da simulação, são os três maiores partidos. PT, PMDB e PSDB, reunidos, passariam de 190 para 273 deputados. O PMDB e o PT teriam bancadas idênticas, cada um controlando quase $20 \%$ da Câmara; ambos ampliariam sua distância em relação ao PSDB. Também ganhariam cadeiras, mas em número menos expressivo, o PSB, o PSOL (graças à votação expressiva no Rio de Janeiro), o PRTB (que opera como linha auxiliar do Senador Fernando Collor e tem força em Alagoas) e o PTdoB (em Minas Gerais).

Todas as outras legendas teriam suas bancadas reduzidas, sendo que PMN, PRP, PEN, PSDC, PTC e PSL deixariam de ter representantes na Câmara dos 
Deputados. Entre os partidos que elegeram 15 ou mais deputados (segundo o resultado oficial), Democratas e Solidariedade seriam os mais atingidos, perdendo $40 \%$ ou mais de suas bancadas. Mas, mesmo com o fim das coligações, permaneceria um grande número de partidos médios ou médio-pequenos. Haveria nada menos do que 13 bancadas entre 5 e 30 deputados, que juntas somariam $31 \%$ da Câmara.

Como consequência do fim das coligações, os partidos tenderiam a ter bancadas mais concentradas em poucas unidades da federação. $\mathrm{O}$ efeito mecânico da regra é evidente, mas há também uma mudança no sistema de incentivos. Hoje, é possível lançar um pequeno número de candidatos em várias Unidades da Federação, com a esperança de que, graças às coligações, alguns sejam eleitos. Sem essa possibilidade, os partidos seriam levados a concentrar esforços, delimitando espaços de atuação, dados os crescentes custos eleitorais (organizativos, materiais e de número de votos necessários) e a pequena capilaridade da maioria dos partidos brasileiros. Um resultado possível seria o fortalecimento dos sistemas partidários subnacionais (cf. Bardi \& Mair 2010). No médio prazo, partidos com bases estaduais diferentes teriam incentivo para se reunir, a fim de ganhar força no parlamento, formando novas legendas que seriam meras federações de organizações locais.

É possível supor que as coligações penalizam o PMDB, mais do que qualquer outro partido, por sua acentuada diversidade interna - ou seja, a descentralização organizativa, junto à estratégia de esforços eleitorais dispersos do partido, levaria a um cenário adverso no quadro simulado. Para legendas coligadas que desejam maximizar o número de seus eleitos, a melhor estratégia é estimar suas chances e concentrar os esforços de campanha num número de candidatos próximo ao das cadeiras que pode realisticamente almejar. Foi o que fez, por exemplo, o PCdoB, desde o início da redemocratização. Em 2014, ele lançou mais de quatro candidatos em apenas quatro unidades da federação; na maioria delas, lançou um ou dois. Esteve sempre coligado a partidos maiores, em quase todas as vezes com o PT, mas em alguns casos com PMDB, PSDB ou DEM. Elegeu dez deputados federais (seriam apenas cinco sem coligações). O PMDB, com grande número de lideranças internas e baixa coesão, dificilmente poderia pensar em uma estratégia de concentração de campanha.

Por outro lado, o PSOL, único partido à esquerda do PT que obteve representação na Câmara dos Deputados, saiu sozinho na maioria das unidades da federação. Em alguns estados importantes, como Minas Gerais, Rio Grande do Sul e São Paulo, esteve junto do PSTU, que poucos votos agregava à chapa; no Ceará, a eles se agregou o PCB. Apenas no Amapá, em que se aliou a PT e PSB, e em Pernambuco, em que esteve junto do PMN, este padrão foi mudado. Por isso, um eventual veto às coligações pouco prejudicaria o partido.

O efeito da proibição de coligações sobre a composição da Câmara dos Deputados não é tão grande devido à fraca nacionalização dos partidos. $\mathrm{Na}$ simulação, como mostra a Tabela 4 , o número de partidos que elegem deputados cai em todas as unidades da federação. Em quase todas, o tamanho da maior bancada partidária cresceria (mantendo-se estável apenas no Espírito Santo, no Piauí e em Santa Catarina). O efeito agregado é minimizado pelo fato de que diferentes partidos elegem deputados em diferentes estados. Os dados da Tabela 3 já indicavam que, com a proibição das coligações, apenas três partidos elegeriam deputados federais em mais da metade das unidades da federação (com as regras atuais, este número chega a 11).

Com ou sem coligações, um mesmo número de legendas elegeria deputados em apenas três ou menos unidades da federação. A proibição das coligações eliminaria seis destes partidos, mas, ao mesmo tempo, o grupo seria reforçado por outras agremiações, que têm força para eleger representantes por conta 
Tabela 4 - Bancadas das Unidades da Federação na Câmara dos Deputados brasileira (2014), de acordo com regras eleitorais alternativas

\begin{tabular}{|c|c|c|c|c|c|c|}
\hline & \multicolumn{2}{|c|}{ Regra atual } & \multicolumn{2}{|c|}{ Sem coligações } & \multicolumn{2}{|c|}{ Alteração } \\
\hline & Partidos & $\begin{array}{c}\text { Maior } \\
\text { bancada }\end{array}$ & Partidos & $\begin{array}{c}\text { Maior } \\
\text { bancada }\end{array}$ & Partidos & $\begin{array}{c}\text { Maior } \\
\text { bancada }\end{array}$ \\
\hline Acre & 5 & 3 & 1 & 8 & -4 & +5 \\
\hline Alagoas & 9 & 1 & 3 & 3 & -6 & +2 \\
\hline Amapá & 8 & 1 & 7 & 2 & -1 & +1 \\
\hline Amazonas & 7 & 2 & 3 & 3 & -4 & +1 \\
\hline Bahia & 16 & 8 & 14 & 10 & -2 & +2 \\
\hline Ceará & 14 & 4 & 6 & 6 & -8 & +2 \\
\hline Distrito Federal & 8 & 1 & 1 & 8 & -7 & +7 \\
\hline Espírito Santo & 9 & 2 & 5 & 2 & -4 & 0 \\
\hline Goiás & 10 & 6 & 4 & 9 & -6 & +3 \\
\hline Maranhão & 17 & 3 & 7 & 6 & -10 & +3 \\
\hline Mato Grosso & 7 & 2 & 1 & 8 & -6 & +6 \\
\hline Mato Grosso do Sul & 6 & 2 & 2 & 4 & -4 & +2 \\
\hline Minas Gerais & 21 & 10 & 15 & 12 & -6 & +2 \\
\hline Pará & 12 & 3 & 7 & 4 & -5 & +1 \\
\hline Paraíba & 10 & 3 & 3 & 7 & -7 & +4 \\
\hline Paraná & 15 & 4 & 12 & 5 & -3 & +1 \\
\hline Pernambuco & 12 & 8 & 7 & 10 & -5 & +2 \\
\hline Piauí & 6 & 3 & 4 & 3 & -2 & 0 \\
\hline Rio de Janeiro & 17 & 8 & 13 & 10 & -4 & +2 \\
\hline Rio Grande do Norte & 8 & 1 & 1 & 8 & -7 & +7 \\
\hline Rio Grande do Sul & 11 & 8 & 9 & 9 & -2 & +1 \\
\hline Rondônia & 6 & 3 & 1 & 8 & -5 & +5 \\
\hline Roraima & 8 & 1 & 1 & 8 & -7 & +7 \\
\hline Santa Catarina & 7 & 5 & 5 & 5 & -2 & 0 \\
\hline São Paulo & 18 & 14 & 16 & 16 & -2 & +2 \\
\hline Sergipe & 8 & 1 & 2 & 4 & -6 & +3 \\
\hline Tocantins & 6 & 3 & 1 & 8 & -5 & +5 \\
\hline
\end{tabular}

Fonte: Os autores, a partir de dados do Tribunal Superior Eleitoral.

própria em poucos locais, mas acrescentavam mais alguns deputados por meio das coligações com legendas maiores.

O resultado oficial das eleições de 2014 mostra que, em seis unidades da federação (Alagoas, Amapá, Distrito Federal, Rio Grande do Norte, Roraima e Sergipe), a dispersão da bancada na Câmara dos Deputados foi total: nenhum partido elegeu mais do que um representante. Com a proibição das coligações, haveria um resultado inverso. Em sete unidades da federação, um único partido alcançaria o quociente eleitoral e, assim, ficaria com todas as cadeiras - o PT no Acre e no Distrito Federal, o PMDB no Rio Grande do Norte, em Rondônia e no Tocantins, o PSDB em Roraima e o PSB no Mato Grosso. É claro que tal resultado é contraintuitivo e, no caso de que a regra de proibição vigorasse, certamente os arranjos eleitorais seriam diferentes. 


\section{Barrando a cláusula de barreira}

A simulação apresentada na seção anterior veta a possibilidade de coligações, mas mantem a cláusula de exclusão vinculada ao quociente eleitoral. Como indicado antes, é uma barreira variável, muito alta nas unidades menores da federação. Sobretudo numa situação como a brasileira, com muitas listas concorrendo às eleições, a vigência de tal barreira pode implicar a retirada de um grande contingente de votos da disputa pelas cadeiras legislativas. De fato, nas eleições de 2014, 44\% dos votos dados a candidatos ou partidos no Amapá e no Acre foram eliminados a priori, uma vez que suas listas não alcançaram o quociente. A proporção de votos "desperdiçados" atingiu 37\% em Roraima, 34\% no Mato Grosso e em Rondônia, 32\% no Distrito Federal. A média nacional das proporções de desperdício de votos foi de $20 \%$ e só ficou abaixo dos dois dígitos em quatro estados (Bahia, Minas Gerais, Rio Grande do Sul e São Paulo). Caso as coligações fossem proibidas, a proporção de votos nos partidos que não alcançariam o quociente e, portanto, não participariam da divisão das cadeiras, ultrapassaria a barreira dos $80 \%$ em várias unidades da federação (e chegaria a 100\% no Amapá, como já indicado), com média nacional na casa dos $43 \%$.

A eliminação da cláusula de barreira vinculada ao quociente eleitoral removeria o problema, mas traria como efeito uma nova ampliação do número de partidos com representação na Câmara dos Deputados. Como se observa pela Tabela 5, ainda assim haveria uma redução da dispersão parlamentar, em comparação com a regra atual, mas menor do que na simulação anterior.

A Tabela 6 indica que o maior beneficiado, de acordo com essa simulação, seria o PT, que, embora seja um partido grande, ainda possui uma capilaridade nacional irregular. Nas regras atuais, o PT ficou sem representantes em seis estados - e, portanto, teria espaço para crescer, com a retirada da cláusula de barreira. Mas as bancadas do PMDB e do PSDB também teriam crescimento significativo, confirmando a percepção de que o maior obstáculo à dispersão parlamentar no Brasil não é a ausência de barreiras mais elevadas e sim a possibilidade de coligações eleitorais.

Outro desenho alternativo que impediria as coligações é a proposta de voto único não-transferível, que ganhou o debate brasileiro sob o nome de "distritão", patrocinada pelo PMDB e, em especial, pelo presidente da Câmara dos Deputados, Eduardo Cunha (PMDB-RJ). Pelo "distritão", seriam eleitos simplesmente os candidatos mais sufragados, independentemente da votação agregada do partido ou coligação ao qual pertencesse. A principal vantagem associada ao sistema é sua fácil legibilidade, uma vez que se julga que o "eleitor comum" tem dificuldade de entender por que um candidato com menos votos (mas vinculado a uma lista mais forte) ganha a cadeira no parlamento e outro, mais bem votado, não. Também evitaria que, graças à presença de um grande

Tabela 5 - Fragmentação partidária na Câmara dos Deputados brasileira (2014), de acordo com regras eleitorais alternativas (atual e sem coligações, mas sem barreira)

\begin{tabular}{lccc}
\hline & Regra atual & $\begin{array}{c}\text { Sem coligações } \\
\text { e sem barreira }\end{array}$ & Alteração \\
\hline Número de partidos & 28 & 25 & -3 \\
Maior bancada & 70 & 90 & +20 \\
Partidos para maioria simples & 5 & 4 & -1 \\
Fracionamento de Rae & 0,924 & 0,905 & $-0,019$ \\
\hline
\end{tabular}

Fonte: Os autores, a partir de dados do Tribunal Superior Eleitoral. 
Tabela 6 - Bancadas partidárias na Câmara dos Deputados brasileira (2014), de acordo com regras eleitorais alternativas (atual e sem coligações, mas sem barreira)

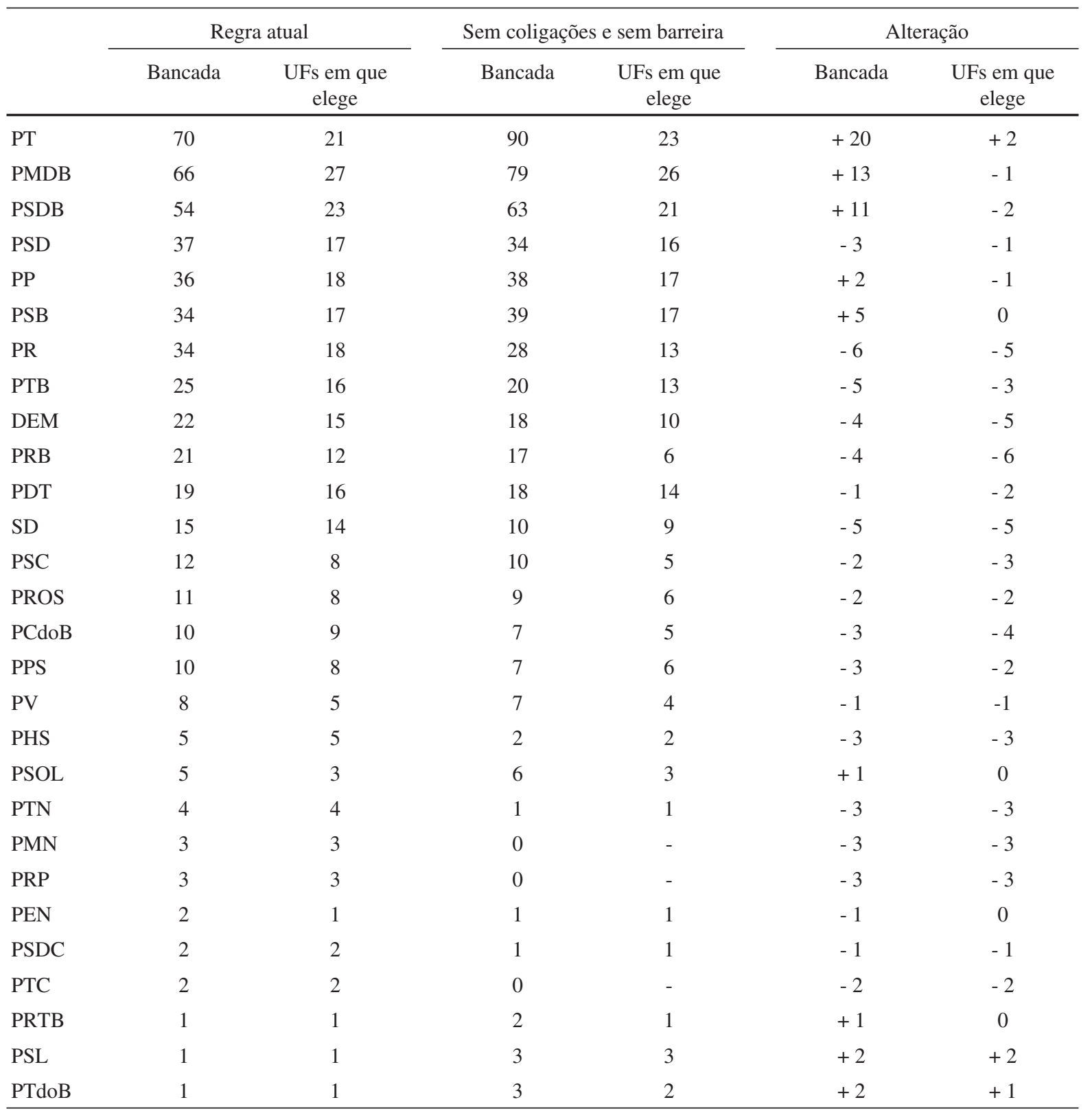

Fonte: Os autores, a partir de dados do Tribunal Superior Eleitoral.

puxador de votos na lista, candidatos com pouquíssimo capital eleitoral fossem vitoriosos. Por exemplo, em 2002, em São Paulo, o 1,6 milhão de votos de Enéas Carneiro deu ao Prona mais quatro deputados federais, um deles com apenas 274 votos.

Mas os inconvenientes da proposta são ainda mais notáveis. O "distritão" personaliza de vez a campanha, tornando os partidos políticos praticamente desnecessários. Na verdade, pode ser visto como um passo necessário para a adoção das candidaturas avulsas, sem vinculação partidária. Tal desvinculação pode ser conveniente para a imagem de candidatos à liderança política, que não precisam assumir diante do público seus compromissos e alianças, projetando uma impressão de "independência" que é positiva, em momentos em que a atividade política é tão mal avaliada. No processo, porém, destrói a ideia de que 
${ }^{5}$ Esse resultado poderia eventualmente ser minimizado, dependendo das regras de acesso à propaganda eleitoral no rádio e na televisão. a eleição apresenta uma disputa entre projetos de sociedade, não um embate de personalidades. Por fim, o "distritão" retira do eleitor a possibilidade do voto em legenda - que, ao contrário do que muitas vezes se imagina, não é algo irrelevante. Em 2014, em algumas unidades da federação, como em São Paulo, o voto em legenda correspondeu a mais de $10 \%$ dos votos válidos.

É bem verdade que na principal experiência internacional com o voto único não-transferível - o Japão, que adotou o sistema entre 1948 e 1993 - o resultado não correspondeu àquilo que especulamos aqui como possíveis consequências para o Brasil, o que se deve à estrutura de incentivos diferenciada dada pelo regime parlamentarista, pelo modelo de financiamento público dos partidos e, em especial, pela "cultura política" japonesa. Cabe observar, porém, que a literatura anota que, se o sistema proporcionou maiorias distendidas para o Partido Liberal Democrata, então dominante, ao mesmo tempo contribuiu para fragmentar a oposição (Reed \& Bolland 1999).

A Tabela 7 mostra que, caso tivesse sido adotado em 2014, o "distritão" levaria a uma redução muito pequena do número de partidos e do índice de fracionamento da Câmara dos Deputados.

Pela simulação, conforme mostra a Tabela 8, o PMDB e o PSD seriam os principais beneficiados, com um acréscimo de cinco deputados para cada um. $\mathrm{O}$ PT, que ganharia duas cadeiras, permaneceria como maior bancada, apenas um deputado à frente do PMDB. Mas é claro que, caso a regra estivesse de fato em vigência, o resultado provavelmente seria uma explosão do número de legendas representadas. Afinal, qualquer candidato com um mínimo de chance na eleição teria um forte incentivo para pilotar sua própria legenda, sem outras lideranças, já que só se beneficiaria de seus próprios votos ${ }^{5}$. Ou seja, mais ainda do que nos casos anteriores, a simulação que resulta nas Tabelas 7 e 8 deve ser lida com precaução.

As simulações apresentadas até aqui mantêm a atual divisão da representação pelas unidades da federação que, como se sabe, penaliza severamente a maior delas - São Paulo, que tem sua bancada diminuída pelo teto de 70 deputados - e infla a presença das menores, graças ao piso mínimo de oito deputados. A Tabela 9 simula a composição da Câmara dos Deputados caso fosse concedida a cada partido uma bancada proporcional à sua votação nacional, isto é, como se o Brasil inteiro formasse um único grande distrito com 513 vagas. Foram somadas as votações dos candidatos de cada partido, bem como os votos dados à legenda, em cada uma das 27 unidades da federação. Nesse caso, a cláusula de barreira determinada pelo quociente eleitoral seria irrisória, inferior a $0,2 \%$. Ainda assim, caso ela fosse considerada, o PSTU ficaria de fora do legislativo federal (e sua cadeira seria transferida para o PMDB).

De forma pouco surpreendente, os números mostram que os principais beneficiados com a proporcionalidade nacional seriam PSDB e PT, que obtiveram as maiores votações no Estado de São Paulo e ampliariam suas bancadas

Tabela 7 - Fragmentação partidária na Câmara dos Deputados brasileira (2014), de acordo com regras eleitorais alternativas (atual e "distritão")

\begin{tabular}{lccc}
\hline & Regra atual & "Distritão" & Alteração \\
\hline Número de partidos & 28 & 26 & -2 \\
Maior bancada & 70 & 72 & +2 \\
Partidos para maioria simples & 5 & 5 & 0 \\
Fracionamento de Rae & 0,924 & 0,920 & $-0,004$ \\
\hline
\end{tabular}

Fonte: Os autores, a partir de dados do Tribunal Superior Eleitoral. 
Tabela 8 - Bancadas partidárias na Câmara dos Deputados brasileira (2014), de acordo com regras eleitorais alternativas (atual e "distritão")

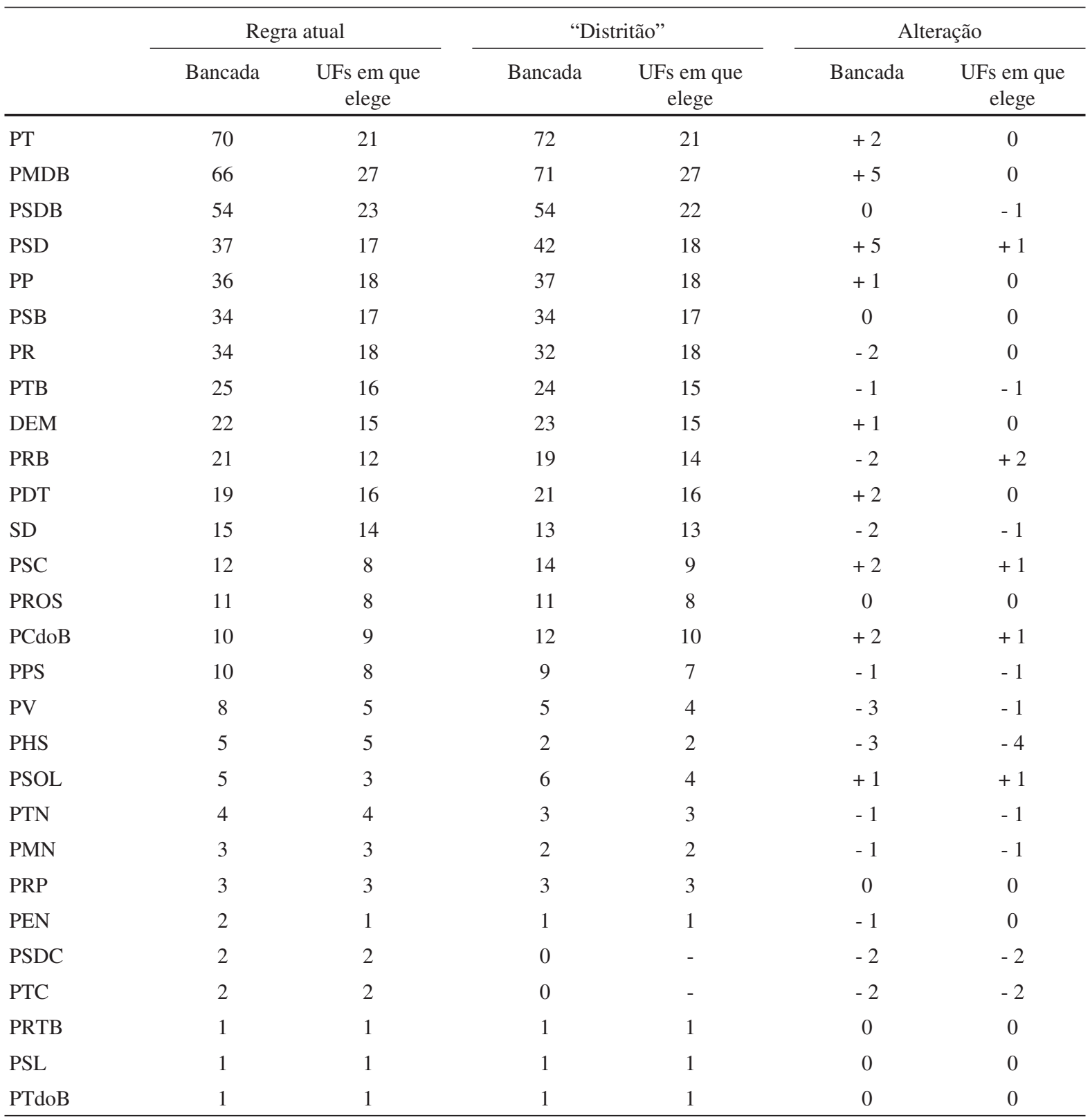

Fonte: Os autores, a partir de dados do Tribunal Superior Eleitoral.

em seis e quatro cadeiras, respectivamente. Também ganharia quatro deputados o PSOL, que fez alguma votação em muitas unidades da federação, sem alcançar o quociente eleitoral, mas agregaria nacionalmente. O PMDB seria o maior perdedor, ficando com oito cadeiras a menos, o que reflete tanto sua votação relativamente baixa em São Paulo quanto o fato de que ele é o maior beneficiário do sistema atual. Dada a sua força distribuída em todo o território, ele ganha com a exclusão dos partidos que não alcançam o quociente eleitoral nas diferentes UFs.

O principal argumento em oposição à proporcionalidade nacional é que ela provavelmente comprimiria a representação das menores unidades da federação - o mesmo argumento, aliás, que é usado para justificar as distorções nas bancadas estaduais na Câmara dos Deputados. A rigor, no ordenamento político 
Tabela 9 - Bancadas partidárias na Câmara dos Deputados brasileira (2014), de acordo com regras eleitorais alternativas (atual e com um único distrito nacional, sem cláusula de barreira)

\begin{tabular}{|c|c|c|c|}
\hline & Regra atual & Distrito único nacional & Alteração \\
\hline PT & 70 & 74 & +4 \\
\hline PMDB & 66 & 58 & -8 \\
\hline PSDB & 54 & 60 & +6 \\
\hline PSD & 37 & 32 & -5 \\
\hline PP & 36 & 33 & -3 \\
\hline PSB & 34 & 34 & 0 \\
\hline PR & 34 & 30 & -4 \\
\hline РТВ & 25 & 21 & -4 \\
\hline DEM & 22 & 22 & 0 \\
\hline PRB & 21 & 24 & +3 \\
\hline PDT & 19 & 19 & 0 \\
\hline SD & 15 & 14 & -1 \\
\hline PSC & 12 & 13 & +1 \\
\hline PROS & 11 & 10 & -1 \\
\hline PCdoB & 10 & 10 & 0 \\
\hline PPS & 10 & 10 & 0 \\
\hline $\mathrm{PV}$ & 8 & 10 & +2 \\
\hline PHS & 5 & 5 & 0 \\
\hline PSOL & 5 & 9 & +4 \\
\hline PTN & 4 & 3 & -1 \\
\hline PMN & 3 & 2 & -1 \\
\hline PRP & 3 & 3 & 0 \\
\hline PEN & 2 & 3 & +1 \\
\hline PSDC & 2 & 2 & 0 \\
\hline PTC & 2 & 1 & -1 \\
\hline PRTB & 1 & 2 & +1 \\
\hline PSL & 1 & 4 & +3 \\
\hline PTdoB & 1 & 4 & +3 \\
\hline PSTU & 0 & 1 & +1 \\
\hline
\end{tabular}

Fonte: Os autores, a partir de dados do Tribunal Superior Eleitoral.

brasileiro, a presença do Senado Federal, em que cada UF possui o mesmo número de representantes, seria suficiente para garantir que as menores não seriam prejudicadas. Seja como for, a ideia de uma representação proporcional à votação dos partidos em todo o território nacional nem é cogitada, talvez porque implicaria uma brutal redução do capital político dos chefes locais.

\section{Conclusões}

Os dados indicam que uma mudança das regras eleitorais que impedisse a formalização de coligações para as eleições proporcionais teria um impacto moderado, mas não desprezível, na redução do número de partidos com representação parlamentar. Ao contrário da introdução de uma cláusula de barreira, que determinaria um patamar arbitrário, essa medida contribuiria para ampliar a representatividade do corpo legislativo. Além disso, uma cláusula de barreira na 
${ }^{6}$ Do ponto de visa do eleitor, a possível concentração de esforços dos partidos em um menor número de UFs levaria à redução da "poluição" de legendas poucos diferenciadas entre si, ampliando a inteligibilidade do processo eleitoral. faixa dos 5\%, por exemplo, aniquilaria legendas com visão programática e cuja contribuição ao debate político é inegável, como é o caso do PSOL. Já a proibição das coligações, segundo a simulação indicou, retiraria da Câmara dos Deputados apenas partidos sem perfil claro e cujas posições já estão amplamente contempladas nas agremiações mais fortes.

Os limites no impacto da medida são de duas naturezas. Por um lado, há os limites institucionais. Os partidos brasileiros são pouco nacionalizados, o que implica que diferentes legendas conquistem cadeiras em diferentes lugares. Essa diversidade é natural, num território tão grande e diversificado - uma nacionalização forçada certamente levaria a arbitrariedades. Mas, além da diversidade de interesses ligados à situação social e econômica de cada ponto do território, há a presença de caciques locais, que escolhem uma sigla para viabilizar seus projetos eleitorais, sem maior consistência programática ${ }^{6}$.

Outro limite institucional se deve à fraca coesão dos partidos no Congresso. A redução do número de legendas não gera necessariamente um processo legislativo simplificado, com negociações mais fáceis, uma vez que boa parte das questões passa por múltiplas bancadas pluripartidárias e por interesses pessoais. Mais uma vez, o remédio possível possui contraindicações. O reforço da autoridade das direções partidárias ou das lideranças de bancada reduz a representatividade democrática da Câmara, uma vez que os deputados têm um incentivo a mais para prestar contas a outros e não a seus constituintes.

Os outros limites são estruturais. As eleições de 2014 colocaram 51 mulheres na Câmara dos Deputados, isto é, ainda menos de 10\%. Entre os eleitos, $80 \%$ se declararam brancos. A imprensa noticiou que um total de 80 deputados assume os mandatos com o compromisso de defender os interesses do latifúndio, ao passo que grupos populacionais majoritários continuam quase carentes de porta-vozes. Em suma, os problemas que se vinculam ao número de partidos representados, embora não sejam desprezíveis, estão longe de ser os fundamentais. Se uma transformação nos mecanismos de representação se orienta a aprimorar a expressão da vontade popular e o controle dos constituintes sobre os eleitos, o caminho mais promissor é buscar a ampliação do debate público, a redução do peso do capital nas decisões políticas e o fortalecimento da sociedade civil, que permitiriam aos eleitores aproveitar de forma mais consistente as oportunidades de escolha que lhes são oferecidas.

Luis Felipe Miguel (luisfelipemiguel@gmail.com) é professor do Instituto de Ciência Política da Universidade de Brasília (UnB) e pesquisador do CNPq. Vínculo Institucional: Instituto de Ciência Política, UnB, Brasília, DF, Brasil.

Pedro Paulo Ferreira Bispo de Assis (pedropaulo_cp@hotmail.com) é Mestrando em Ciência Política pela Universidade de Brasília (UnB). Vínculo Institucional: Instituto de Ciência Política, UnB, Brasília, DF, Brasil.

\section{Referências}

Ames, B., 2003. Os entraves da democracia no Brasil. Rio de Janeiro: FGV Editora.

Bardi, L. \& Mair, P., 2010. Os parâmetros dos sistemas partidários. Revista Brasileira de Ciência Política, 4, pp.227-253.

Duverger, M., 1980. Os partidos políticos. Rio de Janeiro: Zahar Editores.

Limongi, F., 2006. Presidencialismo e governo de coalizão. In L. Avritzer \& F. Anastasia, eds. Reforma política no Brasil. Belo Horizonte: Editora UFMG.

Limongi, F. \& Figueiredo, A., 1994. Partidos políticos na Câmara dos Deputados: 1989-1994. Dados, 38(3), pp.497-525. DOI: 10.1590/s0011-52582009010200002

1998. Bases institucionais do presidencialismo de coalizão. Lua Nova, 44, pp.81-106. DOI: 10.1590/S0102-64451998000200005

Mainwaring, S., 2001. Sistemas partidários em novas democracias: o caso do Brasil. Rio de Janeiro: FGV.

Miguel, L.F., 2010. Accountability em listas abertas. Revista de Sociologia e Política, 37, pp.183-200. DOI: 10.1590/s0104-44782010000300012

2014. Democracia e representação: territórios em disputa. São Paulo: Editora Unesp. 
Mill, J.S., 1995. O governo representativo. São Paulo: Ibrasa.

Nicolau, J., 2005. Partidos na República de 1946: uma réplica metodológica. Dados, 48(3), pp.589-609. DOI: $10.1590 / \mathrm{s} 0011-52582005000300005$

,2007. O sistema eleitoral de lista aberta no Brasil. In J. Nicolau \& T. Power, eds. Instituições representativas no Brasil: balanço e reforma. Belo Horizonte: Editora UFMG.

Reed, S.R. \& Bolland, J.M., 1999. The Fragmentation Effect of SNTV in Japan. In B.N. Grofman; S-C. Lee; E. Winckler \& B. Woodall, eds. Elections in Japan, Korea, and Taiwan under the Single Non-Transferable Vote: The Comparative Study of an Embedded Institution. Ann Arbor: Michigan University Press.

Rodrigues, R., 1995. Barreira legal nos sistemas eleitorais proporcionais. Revista de Informação Legislativa, 126, pp.47-55.

Tavares, J.A.G., 1994. Sistemas eleitorais nas democracias contemporâneas: teoria, instituições, estratégia. Rio de Janeiro: Relume-Dumará.

Young, Y.M., 2000. Inclusion and Democracy. Oxford: Oxford University Press. 
Electoral Coalitions and Fragmentation of Parliamentary Caucuses in Brazil:

Simulations from the 2014 Elections

\section{Abstract}

The article discusses the impact of electoral coalitions in the fragmentation of parliamentary caucuses in the Brazilian House of Representatives and makes simulations on the results of 2014 election, using alternative rules to the distribution of seats. The simulation reveals that, without coalitions, both the number of parties represented in the House and the Rae fractionalization index would fall $21 \%$. Although the simulation has limitations, since the change in the rules would also change the strategies of political agents, it is demonstrated that the veto to coalitions would reduce the dispersion of parliamentary seats, without leading to the adoption of arbitrary measures (such as the introduction of an exclusion clause). On the contrary, the ban on coalitions would help to bring the electoral system to the logic presiding over proportional representation

KEYWORDS: electoral coalitions; Brazilian elections; political parties; proportional representation; electoral reform.

This is an Open Access article distributed under the terms of the Creative Commons Attribution Non-Commercial License which permits unrestricted non-commercial use, distribution, and reproduction in any medium provided the original work is properly cited. 


\section{Apêndice 1 - Relação de siglas}

DEM - Democratas

PCB - Partido Comunista Brasileiro

PCdoB - Partido Comunista do Brasil

PDS - Partido Democrático Social

PDT - Partido Democrático Trabalhista

PEN - Partido Ecológio Nacional

PFL - Partido da Frente Liberal

PHS - Partido Humanista da Solidariedade

PMDB - Partido do Movimento Democrático Brasileiro

PMN - Partido da Mobilização Nacional

PP - Partido Progressista

PPS - Partido Popular Socialista

PR - Partido da República

PRB - Partido Republicano Brasileiro

Prona - Partido de Reedificação da Ordem Nacional

PROS - Partido Republicano da Ordem Social

PRP - Partido Republicano Progressista

PRTB - Partido Renovador Trabalhista Brasileiro

PSB - Partido Socialista Brasileiro

PSC - Partido Social Cristão

PSDB - Partido da Social-Democracia Brasileira

PSDC - Partido Social-Democrata Cristão

PSL - Partido Social Liberal

PSOL - Partido Socialismo e Liberdade

PSTU - Partido Socialista dos Trabalhadores Unificado

PT - Partido dos Trabalhadores

PTB - Partido Trabalhista Brasileiro

PTC - Partido Trabalhista Cristão

PTdoB - Partido Trabalhista do Brasil

PV - Partido Verde

SD - Solidariedade 